\title{
Higher longevity and fecundity of Chrysoperla carnea, a predator of olive pests, on some native flowering Mediterranean plants
}

\author{
Darinka Gonzalez ${ }^{1}$ • Anabela Nave ${ }^{1}$ - Fátima Gonçalves ${ }^{1} \cdot$ Fernando M. Nunes $^{2}$ • \\ Mercedes Campos $^{3} \cdot$ Laura Torres $^{1}$
}

Accepted: 8 April 2016/Published online: 26 April 2016

(C) INRA and Springer-Verlag France 2016

\begin{abstract}
Biological control is the use of natural enemies, such as predators, of crop pests. For instance, Chrysoperla carnea (Stephens) is a major predator of olive grove pests. To favor the abundance of $C$. carnea, flowering plants should provide them with carbohydrates. However, there is a lack of knowledge on the biology of flowering plants that grow in olive groves. Therefore, we studied in the laboratory 11 native Mediterranean plants commonly found in traditional olive orchards as food sources for C. carnea adults. Male and female longevity and female lifetime fecundity were measured on a daily base. Plant nectar and pollen were quantified by highperformance anion-exchange chromatography analysis (HPAEC-PAD). Our results show that the longevity of C. carnea females was higher, of 17 days, when fed with Conopodium majus flowers, and of 14 days when fed with Lonicera hispanica flowers. Female fecundity was higher for C. carnea individuals fed with C. majus, giving 71 eggs, and with Foeniculum vulgare, giving 66 eggs, than for C. carnea individuals fed with L. hispanica (19 eggs) and Asparagus acutifolius (4 eggs). These findings are explained by the higher concentration of trehalose in plant nectar and pollen. To our knowledge, this is the first study evaluating the sugar
\end{abstract}

Darinka Gonzalez

darinkacostagonzalez@gmail.com

1 Centre for the Research and Technology of Agro-Environmental and Biological Sciences, CITAB, University of Trás-os-Montes and Alto Douro, UTAD, Quinta de Prados, 5001-801 Vila Real, Portugal

2 CQVR, Chemistry Research Centre, Chemistry Department, University of Trás-os-Montes and Alto Douro, 5001-801 Vila Real, Portugal

3 Department of Environmental Protection, Estación Experimental de Zaidín, CSIC, Profesor Albareda n 1,18008 Granada, Spain profile and content of Mediterranean flower plants as food resource of $C$. carnea adults indicating that trehalose content in pollen and nectar has a key role in $C$. carnea fecundity and longevity.

Keywords Ecosystem services · Ecological engineering · Olive grove $\cdot$ Trehalose $\cdot$ Chrysoperla carnea

\section{Introduction}

Olive growing is a significant land use in Mediterranean countries with important environmental, social, and economic significance. During the last years, high market pressures, as well as the implementation of specific agricultural measures are encouraging olive growers to intensify production, while marginalizing low-input systems. These processes are conducting to the degradation of natural resources and the loss of biodiversity and landscape values. Notwithstanding, because of the nature of the olive agroecosystem and due to its social and economic position, olive growing, more than any other Mediterranean crop could be a model for sustainable landuse in the Mediterranean region, producing highly valued foodstuffs and environmental benefits, while helping to maintain populations in marginal areas (Manuel et al. 2008; Loumou and Giourga 2003). One approach to achieve farm sustainability is to explore ecosystem services on farmland to increase productivity by replacing some major external inputs, such as chemical insecticides, with alternatives such as biological control of pests. Typically, this is accomplished by the intentional provision of flowering plants and plant communities in managed landscapes to enhance the survival and reproduction of predators and parasitoids. However, enhancing natural enemies through diversification of flower plant species in agroecosystems is not a function of increased botanical 
diversity per se. It can be a waste of effort, time, and money if it does not significantly improve pest control (Jervis et al. 2004). Even worse, it can exacerbate some pest problems Baggen and Gurr (1998). Therefore, screening flowering plants for habitat management drives this kind of work from the often "hit and miss" use of multiple plant species to a more strategic, ecological engineering approach, of which laboratory screening is often used to identify optimal plant species for later field experiments (Jervis et al. 2004).

Although exotic plants are frequently used to support beneficial insects, the use of native plants has many advantages; since these plants are locally adapted, they will have lower water, nutrient, and pest control requirements compared with non-native species (Isaacs et al. 2008). Moreover, the use of these plants directly supports their conservation by encouraging their propagation and reintroduction into agroecosystems where they have been largely eliminated (Isaacs et al. 2008). Finally, in many cultures native plants have also important medicinal, religious, and aesthetic values (Fiedler and Landis 2007).

Green lacewings (Neuroptera: Chrysopidae) are among the most common natural enemies of pest insects in almost all agricultural ecosystems worldwide. In olive orchards, lacewing larvae are major oophagous predators of olive moth, Prays oleae (Bernard) (Campos 2007), and are also known predators of olive scale, Saissetia oleae (Olivier), as well as of minor pests, such as the olive psyllid, Euphyllura olivina (Costa), and the oleander scale Aspidiotus nerii Bouché (Campos 2007 and refs therein). The most common species found in the olive orchard is Chrysoperla carnea s.l. (Campos 2007 and refs therein). In contrast to larvae, $C$. carnea adults are not predaceous, feeding only on floral and extrafloral nectar, pollen, and honeydew (Villenave et al. 2006) (Fig. 1a). Sugar feeding is particularly important to promote their survival, longevity, fecundity, and intrinsic growth rates (Principi and Canard 1984; Wäckers and van Rijn 2012; Gonzalez et al. 2015). Moreover, as recently demonstrated, both longevity and lifetime fecundity differ significantly when the insect where fed different naturally occurring sugars (Gonzalez et al. 2015). Also, it is known that the sugar composition of nectar can have a broad variation concerning their quality and quantity (Petanidou 2007). In addition to the most prevalent sugars, such as sucrose, glucose, and fructose, several others can be found in significant concentrations (Baker and Baker 1983; Petanidou 2005, 2007).

The potential of green lacewings for pest suppression, their natural occurrence in olive orchards and the known importance of natural vegetation patches for their concentrations and conservation (Szentkirályi and Szentkirályi 2001), make them ideal candidates for conservation biological control (Campos 2007). These becomes more evident through the introduction of selected flowering plants in commercial olive orchards, whose non-olive vegetation is usually removed by ploughing or by the use of herbicides early in the season, to reduce competition between olive trees and weeds.

This research was aimed at investigating in laboratory conditions the effect of several native Mediterranean flower species, identified as promising candidates as food sources for C. carnea adults, based on the literature and our observations (Nave et al. 2009; Gonçalves et al. 2012). Specifically, we tested the effects of feeding on these flowering plants on the longevity females and males of $C$. carnea, as well as on its fecundity. Additionally, the sugar composition of each food resource (i.e., nectar and pollen) was determined using highperformance anion-exchange chromatography with pulsed amperometric detection (HPAEC-PAD) analysis. Very little is known about the use of flowering plants as food sources for $C$. carnea van Rijn (2012) tested the suitability of flowers of 16 plant species for lacewings, both in adult longevity and the ability to produce eggs; however, these plant species were from field margin flowers of arable crops. Nave et al. (2016) evaluated 21 flowering weeds from the olive grove agroecosystem from the point of view of $C$. carnea theoretical nectar accessibility. To our knowledge, this is the first study comparing the sugar composition of the nectar and pollen of flowers from several plant species, to provide the necessary

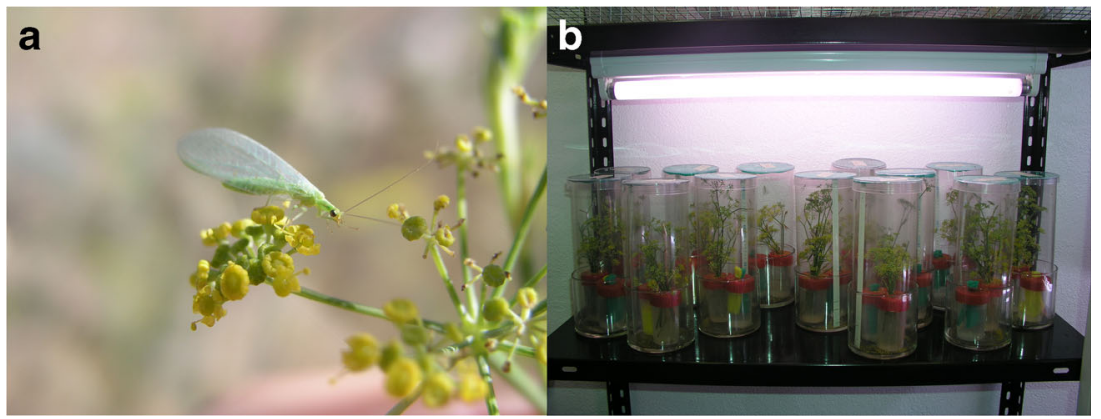

Fig. 1 a Chrysoperla carnea adult feeding on Foeniculum vulgare flowers; both the nectar and pollen of these flowers have trehalose, a nutrient found to enhance predator's performance. b Example of the climate chamber experiment aimed at evaluating the effect of 11 native
Mediterranean plant species on the longevity and fecundity of C. carnea adults. Plants were randomly distributed on the benches within the climate chamber 
food sources for adult lacewings. These results will contribute to identify which specific sugars are important to enhance lacewing performance in olive orchards, a fundamental aspect about which few studies have been done so far ( $\mathrm{Lu}$ et al. 2014).

\section{Material and methods}

\subsection{Plant selection criteria}

We selected 11 species of native Mediterranean plants for the study, using the following criteria: (1) adapted to non-irrigated agricultural field conditions (full sun, moderate drought periods likely), (2) represent a diversity of bloom periods from early through late season, (3) from a variety of plant families, and (4) varied floral color and morphology. The selected plant species were Asparagus acutifolius L. (Asparagaceae), Borago officinalis L. (Boraginaceae), Conopodium majus (Gouan) Loret (Apiaceae), Daucus carota L. (Apiaceae), Echiump plantagineum L. (Boraginaceae), Foeniculum vulgare Mill. (Apiaceae), Lavandula stoechas L. (Lamiaceae), Lonicera hispanica Boiss et Reut. (Caprifoliaceae), Malva neglecta Wallr. (Malvaceae), Raphanus raphanistrum L. (Brassicaceae), and Silene gallica L. (Caryophyllaceae).

\subsection{C. carnea rearing}

C. carnea adults were obtained from eggs collected from a stock colony established with larvae supplied by Köppert Biological Systems (Berkel-en-Rodenrijs, The Netherlands). Larvae were individually reared in Petri dishes on an ad libitum supply of UV sterilized eggs of Ephestia kuehniella Zeller (Lepidoptera: Pyralidae) purchased from Biotop (Valbonne, France), till pupation. The resulting adults were used in the experiments.

\subsection{Effect of different flowers on the longevity and fecundity of $C$. carnea adults}

Newly emerged adults of $C$. carnea $(<24 \mathrm{~h})$ were sexed and confined in pairs within cylinders made with acetate sheets (10 cm diameter and $20 \mathrm{~cm}$ height). Plastic Petri dish formed the top of the container and another plastic cup formed its basis. The Petri dish of the top was lined with green felt as an oviposition substrate and the ventilation inside the cage were assured by multiple perforations in the acetate sheet. Each pair of $C$. carnea was exposed inside the container to a small cylindrical plastic vial $(5 \times 3 \mathrm{~cm})$ with a bouquet made out of a single flower species filled with water and sealed with parafilm, and a small plastic tube as water reservoir with a hole in the lid of these containing a piece of spongy tissue that was permanently submerged in the water, ensuring a continuous water supply for the insects (Fig. 1b). Flowers were collected in the Campus of the University of Trás-os-Montes and Alto Douro. Only those without insect infestation or obvious damage were chosen. Flowering shoots with about $15 \mathrm{~cm}$ length each were cut between 10.00 and $12.00 \mathrm{~h}$, immediately prior to treatment, during their bloom. Because season bloom of the species studied were not synchronized, two different plant groups were collected among the year. A first one in mid May comprising flowering shoots of C. majus, L. stoechas, $L$. hispanica, and S. gallica, and a second one in early September comprising A. acutifolius, B. officinalis, $D$. carota, E. plantagineum, $F$. vulgare, M. neglecta, and $R$. raphanistrum. Excised plants were used for trials mainly to improve logistical and experimental requirements, without compromising the experiment as it was pointed in earlier studies where no evidence was found that its use has an impact on nectar availability in insect's longevity (Wade and Wratten (2007). Fifteen replicates were used per plant species, except for C. majus, for which only 14 replicates were considered due to flower unavailability. All experiments were carried under same conditions in the same climate chamber, at $25 \pm 2{ }^{\circ} \mathrm{C}$, 50-60\% RH, and 16:8 h (L:D) photoperiod. Both flowers and water were changed every 1 to 2 days, to ensure floral resources availability. C. carnea mortality and oviposition was checked daily. The pre-ovipositon and oviposition length periods, as well as the fecundity (total number of eggs laid per female) were registered.

\subsection{Pollen and nectar sugar collection}

For each plant species five samples of daily field nectar were extracted and quantified using capillary micropipettes (Drummond Microcaps ${ }^{\circledR}$ ) under a binocular microscope at $\times 50$ magnification. Afterwards, nectar samples of $1 \mu \mathrm{L}$ obtained from the different flowers were immediately frozen to avoid deterioration. Additionally, plant anthers were collected from flowers using fine forceps under a binocular microscope. Samples from 1.03 to $51.18 \mathrm{mg}$ were stored in Eppendorf vials with identified numbers and immediately frozen.

\subsection{Pollen and nectar preparation for sugar analysis}

Nectar and pollen moisture content was determined by the difference in weight before and after they were freeze-dried. Then for each species, nectar and pollen samples were kept in $3 \mathrm{~mL}$ Eppendorf® caps. After addition of $100 \mathrm{~mL}$ of internal standard solution (2-deoxyglucose $0.05 \%(w / v)), 900 \mu \mathrm{L}$ of ethanol/water (1:1 ratio) were added, and the extraction was carried out by ultrasound process during $5 \mathrm{~min}$. The sample was then centrifuged and the supernatant was transferred to a clean vial. The extraction procedure was repeated by addition of $1 \mathrm{~mL}$ of ethanol/water (1:1 ratio) and ultrasound for $5 \mathrm{~min}$. 
This extraction was repeated twice. All the supernatants were collected in the same vial before analysis.

\subsection{Quantification of nectar and pollen sugar content}

The nectar and pollen soluble sugars were quantified using a previously prepared sugar standard solution of 2-Deoxy-Dglucose (98\%, Sigma-Aldrich) at the concentration of $0.05 \%(w / v)$. The content was then analysed through high performance anion-exchange chromatography with pulsed amperometric detection (HPAEC-PAD, ICS-3000, Dionex). The different sugars separation was performed with a CarboPac PA-20 column $(150 \times 3 \mathrm{~mm})$, with a CarboPac PA20 pre-column (Dionex) using an isocratic elution with a $10 \mathrm{mM} \mathrm{NaOH}$ solution containing $2 \mathrm{mM} \mathrm{Ba}(\mathrm{OH})_{2}$ (Abraão et al. 2013). Calibration curves were constructed for glucose, fructose, and sucrose. The other sugars present in the solutions were quantified by the glucose standard curve. After 10 samples, an additional standard was run to check for deviation from the calibrated values. Sugar identification was determined by comparison of their retention times with that of the standard compounds (trehalose, galactose, glucose, fructose, sucrose, melebiose, and melezitose), and sugar proportions were then determined by integrating the area under the chromatogram peaks. Those sugars not available for identification were classified according to their retention time as monosaccharides and oligosaccharides. The concentrations of the individual sugars were analyzed using the program Chromeleon version 6.40. To adjust sugar contents of each sample, the carbohydrate concentration mass was expressed relative to the total sample mass.

\subsection{Statistical analysis}

To assess the effect of different flower diets on the longevity and reproduction (pre-oviposition and oviposition periods and fecundity) of C. carnea, data were subjected to statistical analysis by using one-way analysis of variance (ANOVA). To homogenize variances, data were transformed by $\log (x+1)$ for fecundity, and $\arcsin (1 / x+1)$ for pre-oviposition and oviposition periods, and $t$ means were compared by a post hoc analysis using Fisher's LSD $(P<0.05)$.

Principal component analysis (PCA) was performed to decompose the original matrix into multiplication of loading (flower nectar and pollen chemical components by HPAECPAD) and scores (flower species samples) matrices. PCA is an unsupervised method of pattern recognition in the sense that no grouping of the data has to be known before the analysis. PCA method explains the maximal amount of variance in the data described by the observed variables based on linear combinations of those groups for the pooled flower species samples. These results enable to highlight several characteristics and correlate them to the nectar and pollens sugar composition of the different flowers species samples analyzed. This method is one of the most often used multivariate methods for data reduction and exploratory analysis on high-dimensional data sets (Jolliffe 2002). Analyses were performed using the software STATISTICA version 8.0 (2007) for MS Windows, from Statsoftß.

\section{Results and discussion}

\subsection{Effect of different flowers on $C$. carnea biological parameters}

The effect of flower species on longevity of $C$. carnea was highly significant for both females $(F=7.201, \mathrm{df}=10$, $P<0.0001)$ and males $(F=3.302, \mathrm{df}=10, P<0.0007)$ (Table 1).

Longevity of C. carnea females fed on C. majus (17.14 \pm 2.40 days) was significantly higher than those fed on other flower species tested, except for L. hispanica (13.53 \pm 1.80 days). Moreover, no significant differences were found in the longevity of individuals fed on $F$. vulgare (12.47 \pm 2.78 days) and $B$. officinalis ( $9.33 \pm 2.50$ days) compared to those fed on L. hispanica. No significant differences were found among the other plant species tested: M. neglecta $(6.68$ \pm 1.50 days), $D$. carota (6.00 \pm 0.73 days), L. stoechas (5.60 \pm 0.32 day), $R$. raphanistrum (5.53 \pm 1.05 days), $S$. gallica $(6.17 \pm 2.12)$, A. acutifolius $(5.27 \pm 0.34$ days), and E. plantagineum ( $4.07 \pm 0.32$ days) (Table 1$)$.

Concerning the longevity of $C$. carnea males, no significant differences were found among the following flowering species: L. hispanica (11.07 \pm 1.64 days), C. majus (10.86 \pm 1.93 days), $F$. vulgare ( $9.87 \pm 2.55$ days), M. neglecta (7.33 \pm 2.16 days), and $B$. officinalis $(7.13 \pm 1.90)$. A significantly lower longevity was found when males were fed on S. gallica (5.41 \pm 1.37$)$, D. carota $(5.27 \pm 0.48$ days), A. acutifolius ( $4.73 \pm 0.31$ days), E. plantagineum (3.93 \pm 0.28 days), and $R$. raphanistrum ( $3.87 \pm 0.49$ days), compared to L. hispanica, C. majus, and F. vulgare. Male longevity was also lower in $L$. stoechas (6.33 \pm 1.32 days) compared to either L. hispanica or C. majus (Table 1).

Oviposition only occurred in individuals fed on C. majus, F. vulgare, L. hispanica, and A. acutifolius. All parameters measured differed significantly among flowering species for the length of the pre-oviposition period $(F=3.808, \mathrm{df}=3$, $P=0.0283)$, the length of the oviposition period $(F=7.97$, $\mathrm{df}=3, P=0.0025)$, and the female fecundity $(F=5.730$, $\mathrm{df}=3, P<0.0062)($ Table 1$)$.

The pre-oviposition period was significantly longer in F. vulgare (12.50 \pm 2.95 days) compared to either $C$. majus (6.21 \pm 1.06 days) or A. acutifolius ( $3.50 \pm 0.50$ days), but did not differ between individuals fed on $F$. vulgare and those fed on L. hispanica (10.33 \pm 4.37 days) (Table 1). The 
Table 1 Average male and female longevity, pre-oviposition period, oviposition period, and fecundity (mean $\pm \mathrm{SE}$ ) of $C$. carnea fed with different flowering plant species

\begin{tabular}{|c|c|c|c|c|c|c|}
\hline Plant species & Longevity of female (days) & $\begin{array}{l}\text { Longevity of male } \\
\text { (days) }\end{array}$ & $n$ & $\begin{array}{l}\text { Pre-oviposition } \\
\text { period (days) }\end{array}$ & $\begin{array}{l}\text { Oviposition period } \\
\text { (days) }\end{array}$ & Fecundity $($ eggs/ $/ q)$ \\
\hline A. acutifolius & $5.27 \pm 0.34 \mathrm{~cd}$ & $4.73 \pm 0.3 \mathrm{c}$ & 2 & $3.50 \pm 0.50 \mathrm{a}$ & $1.00 \pm 0.00 \mathrm{~b}$ & $7.50 \pm 4.50 \mathrm{~b}$ \\
\hline B. officinalis & $9.33 \pm 2.50 \mathrm{bc}$ & $7.13 \pm 1.90 \mathrm{abc}$ & 0 & - & - & - \\
\hline C. majus & $17.14 \pm 2.40 \mathrm{a}$ & $10.86 \pm 1.93 \mathrm{a}$ & 11 & $6.21 \pm 1.06 \mathrm{a}$ & $12.36 \pm 2.37 \mathrm{a}$ & $71.36 \pm 13.35 \mathrm{a}$ \\
\hline D. carota & $6.00 \pm 0.73 \mathrm{~cd}$ & $5.27 \pm 0.48 \mathrm{c}$ & 0 & - & - & - \\
\hline E. plantagineum & $4.07 \pm 0.32 \mathrm{~d}$ & $3.93 \pm 0.28 \mathrm{c}$ & 0 & - & - & - \\
\hline F. vulgare & $12.47 \pm 2.78 b$ & $9.87 \pm 2.55 \mathrm{ab}$ & 6 & $12.50 \pm 2.95 \mathrm{a}$ & $10.5 \pm 2.46 \mathrm{a}$ & $66.33 \pm 15.68 \mathrm{a}$ \\
\hline L. stoechas & $5.60 \pm 0.32 \mathrm{~cd}$ & $6.33 \pm 1.32 \mathrm{bc}$ & 0 & - & - & - \\
\hline L. hispanica & $13.53 \pm 1.80 \mathrm{ab}$ & $11.07 \pm 1.64 \mathrm{a}$ & 3 & $10.33 \pm 4.37 \mathrm{ab}$ & $2.33 \pm 0.88 b$ & $19.00 \pm 9.07 b$ \\
\hline M. neglecta & $6.68 \pm 1.50 \mathrm{~cd}$ & $7.33 \pm 2.16 \mathrm{abc}$ & 0 & - & - & - \\
\hline R. raphanistrum & $5.53 \pm 1.05 \mathrm{~cd}$ & $3.87 \pm 0.49 \mathrm{c}$ & 0 & - & - & - \\
\hline S. gallica & $6.17 \pm 2.12 \mathrm{~cd}$ & $5.41 \pm 1.37 \mathrm{c}$ & 0 & - & - & - \\
\hline$F$ & 7.201 & 3.302 & & 3.8076 & 7.9659 & 5.7303 \\
\hline $\mathrm{df}$ & 10 & 10 & & 3 & 3 & 3 \\
\hline$P$ & $<0.0001$ & $<0.0007$ & & 0.0283 & 0.0025 & $<0.0062$ \\
\hline
\end{tabular}

$n$ is the number of females that oviposited

Fifteen replicates were used per plant species, except for $C$. majus, where only 14 replicates were used due to flower unavailability. Values are mean SE. Means within a column followed by different letters are significantly different. Fisher's LSD $(P<0.05)$ was used. Significant values are in italic format

oviposition period was significantly longer in individuals fed on both $C$. majus $(12.36 \pm 2.37$ days) and $F$. vulgare (10.5 \pm 2.46 days) compared to those fed on either L. hispanica ( $2.33 \pm 0.88$ days) or A. acutifolius $(1.00 \pm 0.00)$. Similar results were obtained for female fecundity. Thus, the number of eggs laid per female was significantly higher in individuals fed on both $C$. majus (71.36 \pm 13.35$)$ and $F$. vulgare (66.33 $\pm 15.68)$ than on those fed on either L. hispanica (19.00

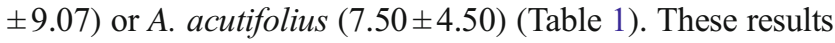
point out that $C$. carnea had a better performance on flowers with high levels of trehalose both simultaneously on nectar and pollen, as for C. majus and F. vulgare, or only on nectar, as for $L$. hispanica. These results are in accordance with those obtained previous study (Gonzalez et al. 2015).

\subsection{Nectar and pollen floral sugar composition and content}

The sugar profiles of nectar and pollen of each flower species are detailed in Table 2. Overall from the 15 flowering species studied, it was possible to identify the presence of seven sugars, which have been previously reported to occur on floral nectars (Baker and Baker 1983). Sugars such as sucrose, glucose, and fructose are considered as common sugars in nectars (Baker and Baker 1983; (Petanidou 2005) while others as, trehalose, galactose, melebiose, and melezitose, are reported as minor sugars (Baker and Baker 1983; (Petanidou 2005). Also, some additional unknown peaks were grouped as monosaccharides and oligosaccharides.
Results shown that trehalose occurred in the nectar and pollen of the three Apiaceae studied (C. majus, D. carota, and $F$. vulgare), as well as in those of $L$. hispanica, S. gallica, A. acutifolius, and L. stoechas (Table 2). This group of plants include the species in which $C$. carnea oviposited (i.e., C. majus, F. vulgare, L. hispanica, and A. acutifolius), and also most of those where longevity was higher, both for female and male (i.e., C. majus, L. hispanica, and F. vulgare). This was particularly evident on C. majus, the plant species whose nectar and pollen had the highest content in trehalose (Table 2). In fact trehalose is the most characteristic sugar in the haemolymph of insects (Lü et al. 2013). Unlike glucose, which is quite toxic at high concentrations due to its reducing power, trehalose can be stored in relatively high concentration in body fluids. This is important because insects have an open circulatory system and lack capillaries in their organs, which are bathed by the haemolymph instead (Becker et al. 1996). Moreover, several studies indicate that trehalose plays a crucial role in the regulation of insect reproduction, growth, and development (Clegg and Evans 1961); (Wyatt 1967); (Thompson and Dahlman 1999; Lü et al. 2013; Xu et al. 2013). Also, the use and concentration of trehalose in insect haemolymph influence many physiological processes, which determine the rate of energy expenditure during flight (Clegg and Evans 1961), chitin synthesis in the molting process (Candy and Kilby 1962), and resistance to cold (Wyatt 1967). Moreover, the concentration of trehalose has been reported to influence the selection of insect food and feeding 


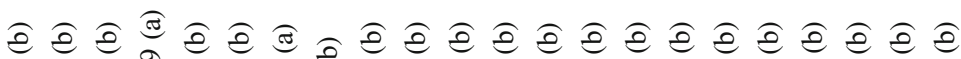

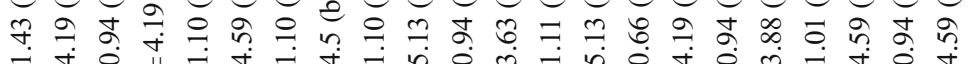

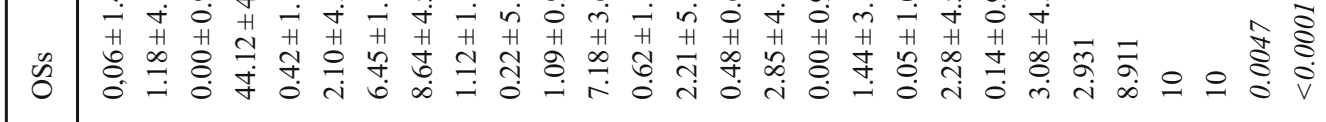

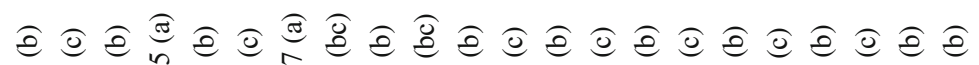

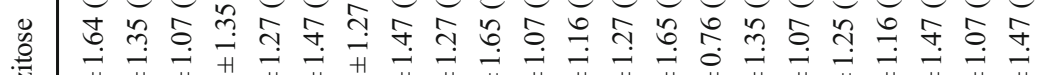

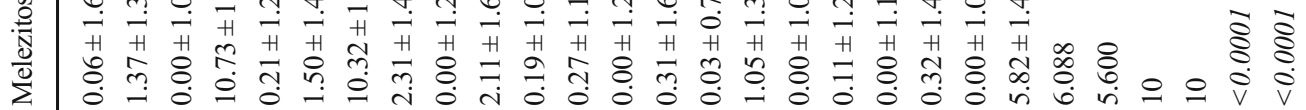

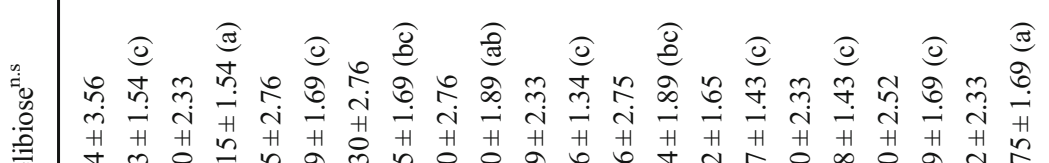

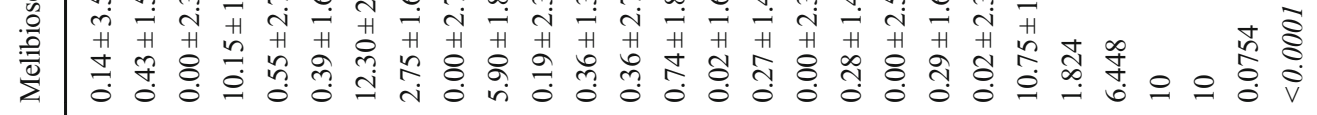

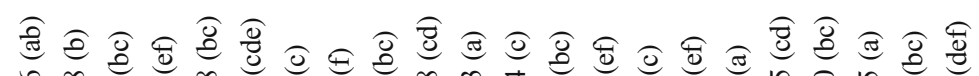

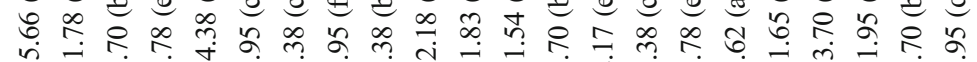

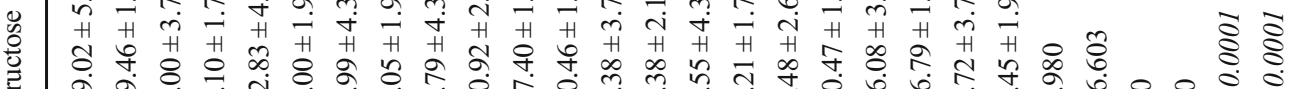

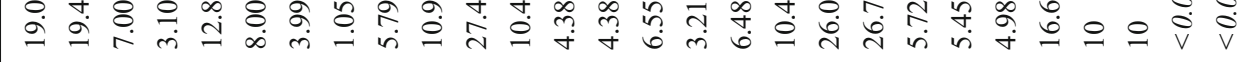

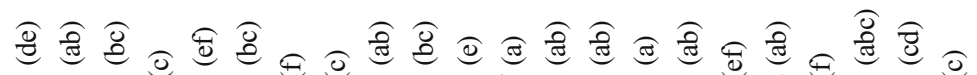

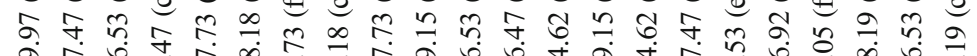

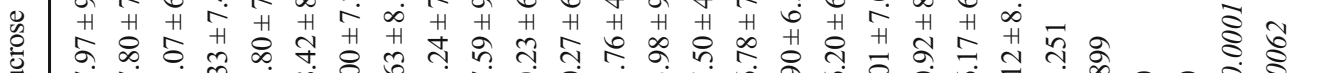

ते

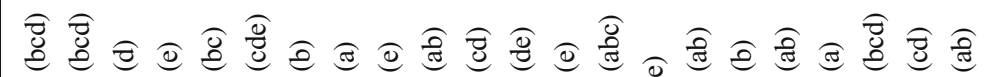

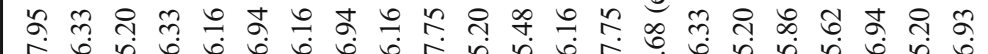

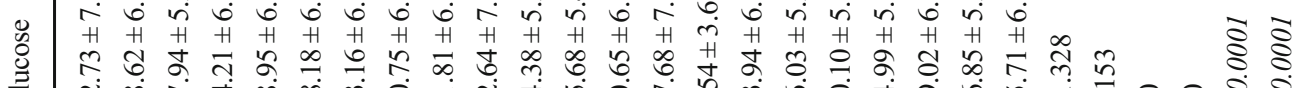

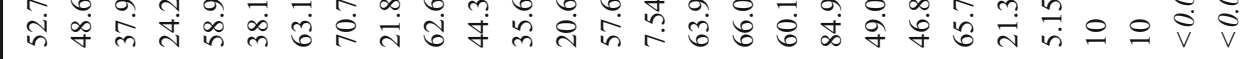

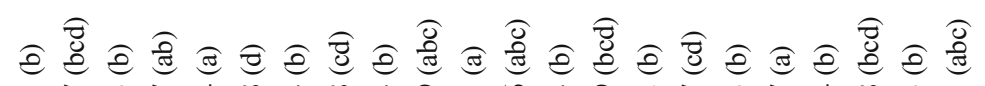

彳

\&. 궁

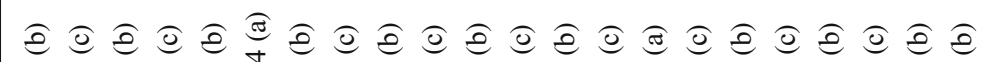

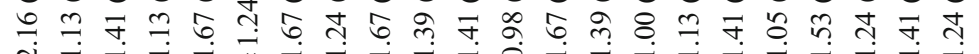

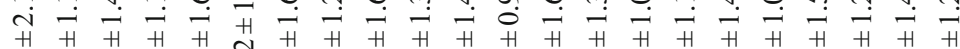

o.

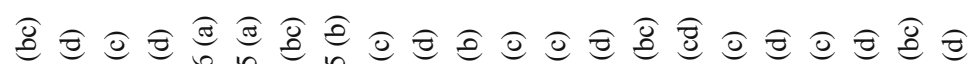

กิษ

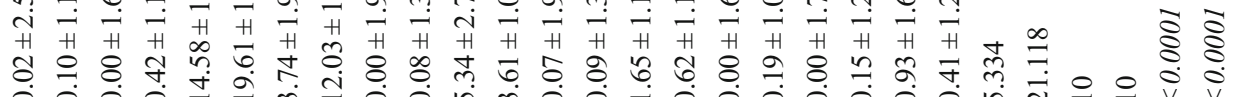

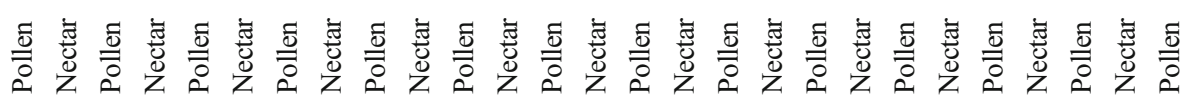


behavior (Thompson and Dahlman 1999). Lü et al. (2013) demonstrated that the parasitoid Trichogramma dendrolimi (Hymenoptera: Trichogrammatidae) developmental parameters as well as numbers of produced adults were increased in artificial medium supplemented with trehalose even when the proportion of pupal haemolymph was reduced. Xu et al. (2013) found that feeding trehalose but not glucose extended the starvation survival, in the red flour beetle, Tribolium castaneum (Coleoptera: Tenebrionidae), which suggests that in addition to being an energy source, trehalose plays also an important role in beetle starvation resistance.

\subsection{Effect of nectar and pollen floral sugar content on $C$. carnea reproduction and longevity}

The chemical composition of both pollen and nectar previously determined by direct analysis of floral sugar contents (Table 2) was used as chemical descriptors. The objective was to evaluate if some of the sugars that naturally occur in the flower species analyzed could explain the differences in the biology performance of $C$. carnea regarding adult longevity and fecundity. PCA of all the chemical components of pollen sugars and $C$. carnea biological parameters yielded four principal components explaining $>70 \%$ of the total variance in the original data set. In the new PCs, the sample loading values express how well those correlate with the original variables. Here, we only focus the ones that have positive correlation (loading values $>+0.75$ ). For nectar sugar contents, the first PC (PC1), which explains $24 \%$ of the total variance, correlates positively with trehalose, C. carnea fecundity, and male and female longevity. For pollen sugar contents, PC1 explains $24.3 \%$ of the total variance and correlates positively with trehalose, monosaccharides, and C. carnea fecundity, as well as with male and female longevity (Fig. 2a, b).

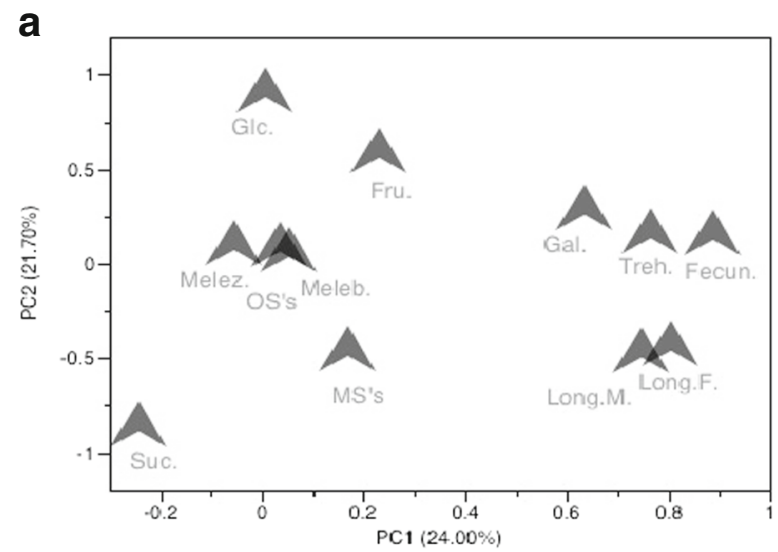

Legend: MS's - monosaccharides; Treh. - trehalose; Gal. - galactose, Glu. - glucose, Fru. - fructose, Suc. - sucrose, Meleb. - melebiose, Melez. - melezitose, OS's oligosaccharides, Fecund. - female C. carnea fecundity, Long M - C. carnea male longevity, and Long. F. - C. carnea female longevity.
Fig. 2 a Nectar scatter plot obtained by representing PC1 vs. PC2. b Pollen score plot obtained by representing PC1 vs. PC2. MSs monosaccharides, Treh. trehalose, Gal. galactose, Glu. glucose, Fru.
For nectar sugar contents, PC2 explains $21.7 \%$ of the total variance and correlates positively with glucose and negatively with sucrose. For pollen sugar contents, PC2 explains $13.48 \%$ of the total variance and correlates negatively with melebiose and melezitose (Fig. 2 a, b). In the remaining PC3 and PC4, none of the variables was decisive. The projection of flower species samples according to their sugar content and C. carnea biological parameters in $\mathrm{PC} 1$ and $\mathrm{PC} 2$ scores are presented in Fig. 3a for nectars and Fig. $3 \mathrm{~b}$ for pollens. For nectar, there is a clear clustering of $C$. majus, $F$. vulgare, and L. hispanica samples with positive $\mathrm{PC1}$ score, meaning that the nectars of these flowers, which are rich in trehalose are also those that allowed a higher fecundity and longevity in C. carnea; on the other hand, samples with negative PC1 scores are from nectars with a low amount of trehalose and also those from flowers in which the fecundity and longevity of $C$. carnea were lower. For the pollen, a similar trend is observed, with a sample from $C$. majus presenting a high PC1 score corresponding to a high amount of trehalose and also a high fecundity and longevity of $C$. carnea. From the pooled data set, both pollen and nectar sugar composition were similar for each of the flower species tested with exception for B. officinalis $\left(R^{2}=0.00079, P \geq 0.9427\right)$, E. plantagineum $\left(R^{2}=0.16824, P \geq 0.2729\right)$, L. hispanica $\left(R^{2}=0.11656, P \geq 0.3685\right)$, S. gallica $\left(R^{2}=0.39383\right.$, $P \geq 0.0704)$. Nevertheless, despite these dissimilarities and with exception for L. hispanica, C. carnea biological parameter performances were poor, with low longevities and no oviposition. This result is supported by the projection of flower species samples according to their nectar sugar content and C. carnea biological parameters (Fig. 3a). Nevertheless, the reasons for the poor performance of $C$. carnea individuals provided with flowers of $D$. carota, despite the trehalose content found in its nectar and pollen, remain speculative. Both the nectar and pollen of this plant species are readily

b

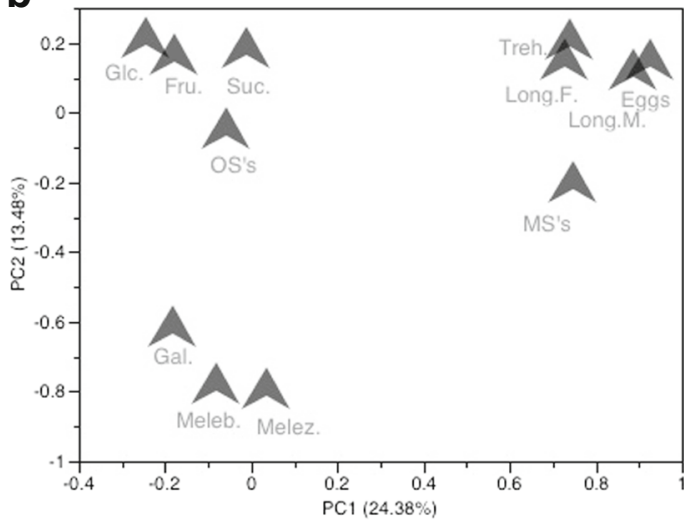

fructose, Suc. sucrose, Meleb. melebiose, Melez. melezitose, OSs oligosaccharides, Fecund. female C. carnea fecundity, Long $M C$. carnea male longevity, Long. F. C. carnea female longevity 
a

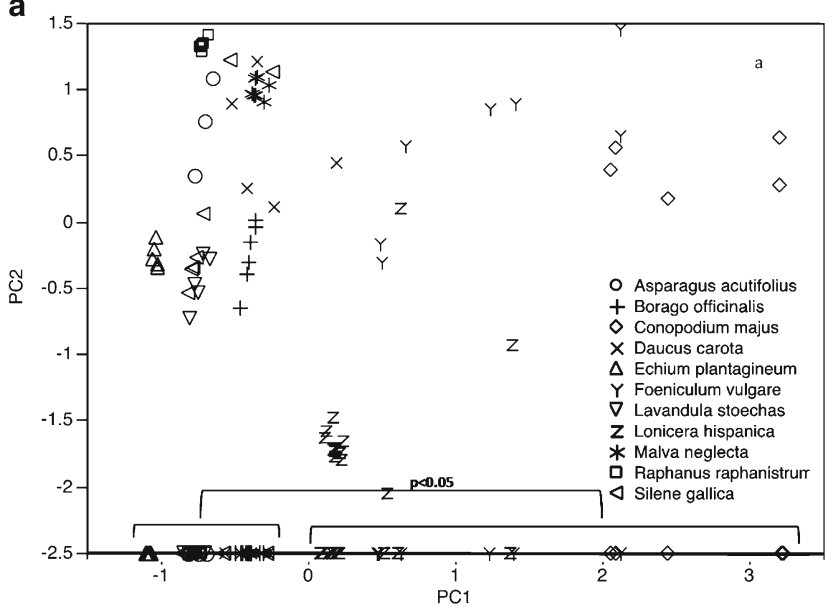

b

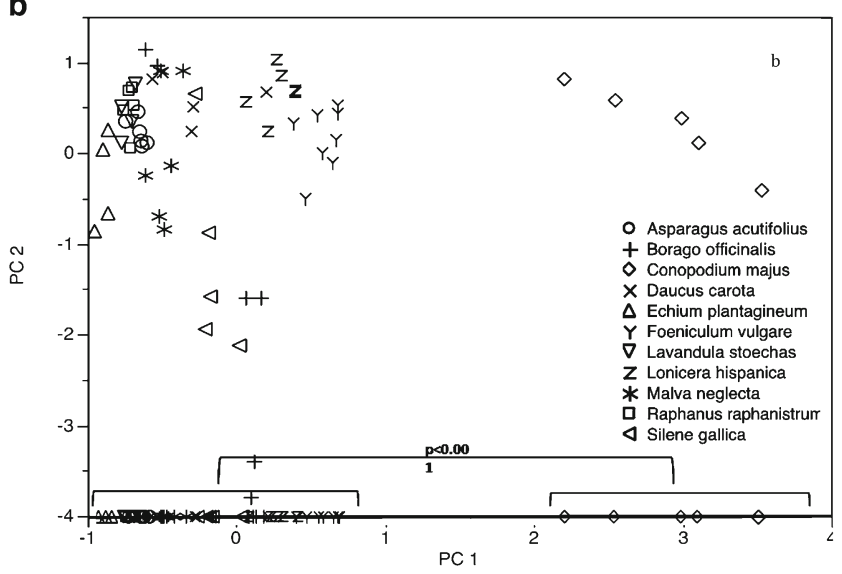

Fig. 3 a Projection of nectar flower species samples according to their sugar content in PC1 and PC2 sample scores. b Projection of pollen flower species samples according to their sugar content in PC1 and PC2 sample scores

accessible, and the flowers are visited by a large diversity of insects, including Diptera, Hymenoptera, Coleoptera, and other generally small insects (Lamborn and Ollerton 2000). The use of $D$. carota nectar by insects is reported in the literature. For example, Winkler et al. (2009) found that D. carota was successfully exploited by the parasitoid Cotesia glomerata (Hymenoptera: Braconidae), but not by the herbivore Pieris rapae (Lepidoptera: Pieridae). Bertolaccini et al. (2008) found that the egg production of Hippodamia variegata (Coleoptera: Coccinellidae) on plants with aphids increased when flowers of Brassica and Sonchus were present compared to flowers of Daucus. It can be concluded from the above referred studies that feeding on $D$. carota flowers can selectively benefit some insect groups, while some others such as likely $C$. carnea are not benefited. The particular morphology of the inflorescence of $D$. carota may explain these results. In fact, this species is unusual among the Apiaceae. In about $90 \%$ of individuals, the florets of the central umbellet are pink or purple in color (Lamborn and Ollerton 2000), presenting a marked contrast to the surrounding umbellets, which are generally white.
Goulson et al. (2009) concluded from their studies that these dark central florets are adaptative and can function as an insect attractant for some insect groups by acting as an insect mimic.

The composition of the nectar and/or pollen of $D$. carota can also play a role in their suitability for different groups of insects. Thus, while sugar constitutes an important component in nectar and pollen, they include a myriad of other compounds, including not only other primary metabolites, such as amino acids, proteins, and lipids that are used to attract pollinators, but also secondary metabolites, such as alkaloids, phenolics, and non-protein amino acids, that could repel nectar thieves (Kessler and Baldwin 2007). Also, biogenic volatile organic compounds (BVOCs) (e.g., terpenoids, phenylpropanoids/benzenoids, fatty acid derivatives, and amino acid derivatives) (Farré-Armengol et al. 2013) produced and emitted by plants, mainly to attract pollinators (Schiestl 2010), can act as "filters" that select effective pollinators and deter detrimental (thieves and herbivores) and neutral floral visitors (generalist pollinators carrying heterospecific pollen) (Junker and Blüthgen 2010).

\section{Conclusion}

Our results showed that from the 11 flowering plant tested under laboratory conditions only four of them can be considered suitable natural food resource to enhance C.carnea biological parameters and therefore promote populations growth. C.carnea lifetime fecundity was only promoted on C. majus, F. vulgare, L. hispanica, and A. acutifolius, and its longivity was significantly increased on three of them, i.e., C. majus, $F$. vulgare, and $L$. hispanica. These results indicate that the nectar and pollen resource of those plants are both accessible and nutritionally suitable to be used by the adult insects (Wäckers and van Rijn 2012). Additionally, the different season bloom of these four plant species ensures that $C$. carnea adults will have quality resource food in the field during the driest and hot time of the year, i.e., from May to September.

Results also point out that the nutritional suitability of the reported plants is related to the high levels of trehalose found in their nectar or pollen. This is, as far as we know, the first time that trehalose is reported as having a key role in enhancing C.carnea biological performance using Mediterranean native flowering plant species experiments. As the demonstration of the effect of flowering plants on life table parameters is considered the best proof that these resources benefit a biological control agent (Wäckers and van Rijn 2012), our results are of great importance since it can support development of habitat management strategies aimed to maximize conservation biological control of olive pests. Although, these results show that these particular plants are very good food sources to C.carnea, their ecological infrastructure suitability needs field test confirmations. Moreover, used as ecological 
infrastructures in the olive grove, the above mentioned plant species have the advantage of offering ecotourism opportunities and thus an additional revenue for olive growers. $L$. hispanica has a high aesthetic value due to the beauty of its flowers, while C. majus, F. vulgare, and A. acutifolius are wild edible plants. Moreover, according to Pardo-deSantayana et al. (2007) citing several authors, there has been renewed or increasing interest in consuming wild food plants, consumption being determined mainly by the pleasure of gathering wild resources, recreating traditional practices, and enjoying characteristic flavors. This, together with the recent developments in rural tourism and the attention paid to healthy properties of natural foods has increased interest in wild edible plants as potential new food sources (Tardío et al. 2006). Some of these plants are increasingly popular as delicacies, local specialities, gourmet food, and local food. For example, in the case of A. acutifolius, both its demand and supply are increasing in many European regions (Pardo-de-Santayana et al. 2007).

Acknowledgments This research is part of the $\mathrm{PhD}$ graduate studies of A.N. which was partially funded by grant SFRH/BD/34394/2008, with partial funding by FEDER funds via Programa Operacional Factores de Competitividade COMPETE (FCOMP-01-0124-FEDER-008685) and national funds via FCT - Fundação para a Ciência e Tecnologia, through project PTDC/AGR-AAM/100979/2008. Thanks to Köppert Biological Systems that kindly provide C. carnea used in this study, as well as to $\mathrm{M}$. Conceição Rodrigues for the support given in the collection of data.

\section{References}

Abraão AS, Lemos AM, Vilela A, Sousa JM, Nunes FM (2013) Influence of osmotic dehydration process parameters on the quality of candied pumpkins. Food Bioprod Process 91(4):481-494. doi:10.1016/j.fbp. 2013.04.006

Baggen LR, Gurr GM (1998) The Influence of food on Copidosoma koehleri (Hymenoptera: Encyrtidae), and the use of flowering plants as a habitat management tool to enhance biological control of potato moth, phthorimaea operculella (Lepidoptera: Gelechiidae). Biol Control 11(1):9-17. doi:10.1006/bcon.1997.0566

Baker HG, Baker I (1983) Floral nectar sugar constituents in relation to pollinator type. In: Jones CE, Little RJ (eds) Handbook of experimental pollination biology. Van Nostrand-Reinhold, New York, pp $117-141$

Becker A, Schlöder P, Steele JE, Wegener G (1996) The regulation of trehalose metabolism in insects. Experientia 52(5):433-439. doi:10. 1007/bf01919312

Bertolaccini I, Núñez-Pérez E, Tizado EJ (2008) Effect of wild flowers on oviposition of Hippodamia variegata (Coleoptera: Coccinellidae) in the laboratory. J Econ Entomol 101(6):1792-1797. doi:10.1603/ 0022-0493-101.6.1792

Campos M (2007) Lacewings in Andalusian olive orchards. In: McEwen P, New TR, Whittington AE (eds) Lacewings in the crop environment. Cambridge University Press, Cambridge, pp 492-497

Candy D, Kilby B (1962) Studies on chitin synthesis in the desert locust. J Exp Biol 39(1):129-140
Clegg JS, Evans DR (1961) Blood trehalose and flight metabolism in the blowfly. Science 134(3471):54-55. doi:10.1126/science.134.3471. 54

Farré-Armengol G, Filella I, Llusia J, Peñuelas J (2013) Floral volatile organic compounds: between attraction and deterrence of visitors under global change. Perspect Plant Ecol Evol Syst 15(1):56-67. doi:10.1016/j.ppees.2012.12.002

Fiedler AK, Landis D (2007) Attractiveness of Michigan native plants to arthropod natural enemies and herbivores. Environ Entomol 36(4): 751-765. doi:10.1603/0046-225x(2007)36[751:aomnpt]2.0.co;2

Gonçalves F, Rodrigues M, Nave A, Falco V, Arnaldo P, Torres L (2012) Evaluation of native plant species from the olive agro ecosystem to enhance conservation biological control. In: Revista de Ciências Agrárias (Portugal), vol 2. Sociedade de Ciências Agrárias de Portugal, pp 250-254. doi:10.1017/S0007485315001091

Gonzalez D, Nave A, Gonçalves F, Nunes FM, Campos M, Torres L (2015) Effects of ten naturally occurring sugars on the reproductive success of the green lacewing, Chrysoperla carnea. BioControl 61(1):57-67. doi:10.1007/s10526-015-9694-z

Goulson D, McGuire K, Munro EE, Adamson S, Colliar L, Park KJ, Tinsley MC, Gilburn AS (2009) Functional significance of the dark central floret of Daucus carota (Apiaceae) L.; is it an insect mimic? Plant Species Biol 24(2):77-82. doi:10.1111/j.1442-1984.2009. 00240.x

Isaacs R, Tuell J, Fiedler A, Gardiner M, Landis D (2008) Maximizing arthropod-mediated ecosystem services in agricultural landscapes: the role of native plants. Front Ecol Environ 7(4):196-203. doi:10. $1890 / 080035$

Jervis MA, Lee JC, Heimpel GE (2004) Use of behavioural and lifehistory studies to understand the effects of habitat manipulation. In: Gurr GM, Wratten SD, Altieri MA (eds) Ecological engineering for pest management: advances in habitat manipulation for arthropods. CSIRO Publishing, Melbourne, pp 65-100

Jolliffe I (2002) Principal component analysis. Wiley Online Library, Springer Science \& Business Media, pp 487

Junker RR, Blüthgen N (2010) Floral scents repel facultative flower visitors, but attract obligate ones. Ann Bot. doi:10.1093/aob/mcq045

Kessler D, Baldwin IT (2007) Making sense of nectar scents: the effects of nectar secondary metabolites on floral visitors of Nicotiana attenuata. Plant J 49(5):840-854. doi:10.1111/j.1365-313X.2006. 02995.x

Lamborn E, Ollerton J (2000) Experimental assessment of the functional morphology of inflorescences of Daucus carota (Apiaceae): testing the 'fly catcher effect'. Funct Ecol 14(4):445-454. doi:10.1046/j. 1365-2435.2000.00440.x

Loumou A, Giourga C (2003) Olive groves: the life and identity of the Mediterranean. Agric Hum Values 20(1):87-95. doi:10.1023/ A: 1022444005336

Lü X, Han SC, Li LY, Grenier S, Clercq P (2013) The potential of trehalose to replace insect hemolymph in artificial media for Trichogramma dendrolimi (Hymenoptera: Trichogrammatidae). Insect Sci 20(5):629-636. doi:10.1111/j.1744-7917.2012.01566.X

Lu ZX, Zhu PY, Gurr GM, Zheng XS, Read DM, Heong KL, Yang YJ, Xu HX (2014) Mechanisms for flowering plants to benefit arthropod natural enemies of insect pests: prospects for enhanced use in agriculture. Insect Sci 21(1):1-12. doi:10.1111/1744-7917.12000

Manuel ABN, Gomez-Limon JA, Kallas Z, Nekhay O (2008) Demand for non-commodity outputs from mountain olive groves. Agric Econ Rev 9(1):5-23

Nave A, Crespí A, Campos M, Torres L, Sousa Ed, Calha I, Moreira I, Monteiro A, Rodrigues L, Portugal J (2009) Olive grove weeds with potential interest in the natural control of the olive moth, Prays oleae. In: XII Congresso da Sociedad Española de Malherbologia (SEMh), XIX Congresso da Asociacion Latinoamericana de Malezas (ALAM), II Congresso Iberico de Ciencias de las Malezas (IBCM), Herbologia e Biodiversidade numa Agricultura 
Sustentável, Lisboa, Portugal, 10 a 13 de Novembro de 2009. Volume 1 and Volume 2. Sociedad Española de Malherbología (Spanish Weed Science Society), pp 39-42

Nave A, Gonçalves F, Crespí AL, Campos M, Torres L (2016) Evaluation of native plant flower characteristics for conservation biological control of Prays oleae. Bull Entomol Res First View pp 1-9. doi: 10.1017/S0007485315001091

Pardo-de-Santayana M, Tardío J, Blanco E, Carvalho AM, Lastra JJ, San Miguel E, Morales R (2007) Traditional knowledge of wild edible plants used in the northwest of the Iberian Peninsula (Spain and Portugal): a comparative study. J Ethnobiol Ethnomed 3(1):1. doi: 10.1186/1746-4269-3-27

Petanidou T (2005) Sugars in Mediterranean floral nectars: an ecological and evolutionary approach. J Chem Ecol 31(5):1065-1088. doi:10. 1007/s10886-005-4248-y

Petanidou T (2007) Ecological and evolutionary aspects of floral nectars in Mediterranean habitats. In: Nectaries and nectar. Springer, pp 343-375. doi:10.1007/978-1-4020-5937-7 8

Principi MM, Canard M (1984) Feeding habits. In: Canard M, Séméria Y, New TR (eds) Biology of chrysopidae. Dr. W. Junk Publishers, The Hague, pp 77-92

Schiestl FP (2010) The evolution of floral scent and insect chemical communication. Ecol Lett 13(5):643-656. doi:10.1111/j.14610248.2010.01451.x

Szentkirályi F, Szentkirályi F (2001) Lacewings in vegetables, forests, and other crops. In: McEwen P, New TR, Whittington AE (eds) Lacewings in the crop environment. Cambridge University Press, Cambridge, pp 239-291. doi:10.1017/CBO9780511666117.012

Tardío J, Pardo-De-Santayana M, Morales R (2006) Ethnobotanical review of wild edible plants in Spain. Bot J Linn Soc 152(1):27-71. doi:10.1111/j.1095-8339.2006.00549.x
Thompson S, Dahlman D (1999) Blood sugar formation due to abnormally elevated gluconeogenesis: aberrant regulation in a parasitized insect, Manduca sexta Linnaeus. Biochim Biophys Acta (BBA) Mol Basis Dis 1454(2):133-142. doi:10.1016/S0925-4439(99)00031-9

van Rijn PC (2012) The suitability of field margin flowers as food source for Chrysoperla lacewings. IOBC/WPRS Bull 75:213-216

Villenave J, Deutsch B, Lode T, Rat-Morris E (2006) Pollen preference of the Chrysoperla species (Neuroptera: Chrysopidae) occurring in the crop environment in western France. Eur J Entomol 103(4):771777. doi:10.14411/eje.2006.104

Wäckers FL, van Rijn PC (2012) Pick and mix: selecting flowering plants to meet the requirements of target biological control insects. In: Geoff MG, Wratten SD, Snyder WE (eds) Biodiversity and insect pests: key issues for sustainable management. Wiley-Blackwell, Oxford, pp 139-165. doi:10.1002/9781118231838.ch9

Wade MR, Wratten SD (2007) Excised or intact inflorescences? Methodological effects on parasitoid wasp longevity. Biol Control 40(3):347-354. doi:10.1016/j.biocontrol.2006.08.015

Winkler K, Wäckers FL, Kaufman LV, Larraz V, van Lenteren JC (2009) Nectar exploitation by herbivores and their parasitoids is a function of flower species and relative humidity. Biol Control 50(3):299 306. doi:10.1016/j.biocontrol.2009.04.009

Wyatt G (1967) The biochemistry of sugars and polysaccharides in insects. Adv Insect Physiol 4:287-360. doi:10.1016/S0065-2806(08) 60210-6

Xu J, Sheng Z, Palli SR (2013) Juvenile hormone and insulin regulate trehalose homeostasis in the red flour beetle, Tribolium castaneum. PLoS Genet 9(6):e1003535. doi:10.1371/journal.pgen.1003535 